\title{
US CDC Real-Time Reverse Transcription PCR Panel for Detection of Severe Acute Respiratory Syndrome Coronavirus 2
}

\author{
Xiaoyan Lu, Lijuan Wang, Senthilkumar K. Sakthivel, Brett Whitaker, \\ Janna Murray, Shifaq Kamili, Brian Lynch, Lakshmi Malapati, Stephen A. Burke, \\ Jennifer Harcourt, Azaibi Tamin, Natalie J. Thornburg, Julie M. Villanueva, Stephen Lindstrom
}

\begin{abstract}
Severe acute respiratory syndrome coronavirus 2 (SARS-CoV-2) was identified as the etiologic agent associated with coronavirus disease, which emerged in late 2019. In response, we developed a diagnostic panel consisting of 3 real-time reverse transcription PCR assays targeting the nucleocapsid gene and evaluated use of these assays for detecting SARS-CoV-2 infection. All assays demonstrated a linear dynamic range of 8 orders of magnitude and an analytical limit of detection of 5 copies/reaction of quantified RNA transcripts and $1 \mathrm{x}$ $10^{-1.5} 50 \%$ tissue culture infectious dose $/ \mathrm{mL}$ of cell-cultured SARS-CoV-2. All assays performed comparably with nasopharyngeal and oropharyngeal secretions, serum, and fecal specimens spiked with cultured virus. We obtained no false-positive amplifications with other human coronaviruses or common respiratory pathogens. Results from all 3 assays were highly correlated during clinical specimen testing. On February 4, 2020, the Food and Drug Administration issued an Emergency Use Authorization to enable emergency use of this panel.
\end{abstract}

$\mathrm{O}^{\prime}$ December 31, 2019, an outbreak of an unexplained acute respiratory disease, later designated coronavirus disease (COVID-19), was reported in Wuhan, China (1). On January 7, 2020, a novel coronavirus, severe acute respiratory syndrome coronavirus 2 (SARS-CoV-2), previously known as 2019-nCoV, was identified as the causative agent of the outbreak

Author affiliations: Centers for Disease Control and Prevention, Atlanta, Georgia, USA (X. Lu, B. Whitaker, S.A. Burke,

J. Harcourt, A. Tamin, N.J. Thornburg, J.M. Villanueva,

S. Lindstrom); Synergy America, Inc., Atlanta (L. Wang, S. Kamili); Eagle Contracting, Atlanta (S.K. Sakthivel, J. Murray, B. Lynch); Leidos, Atlanta (L. Malapati); Battelle, Atlanta (S.A. Burke)

DOI: https://doi.org/10.3201/eid2608.201246
(2). On January 10, 2020, a SARS-CoV-2 genome sequence was shared with the global scientific community through an online resource (3). The virus was genetically most closely related to SARS-CoV and SARS-related bat and civet coronaviruses within the family Betacoronavirus, subgenus Sarbecovirus $(4,5)$.

To support the potential public health emergency response to COVID-19, the Centers for Disease Control and Prevention (CDC) developed and validated a real-time reverse transcription PCR (rRT-PCR) panel based on this SARS-CoV-2 genome sequence (3). The panel targeted the nucleocapsid protein $(\mathrm{N})$ gene of SARS-CoV-2. The rRT-PCR panel was validated under the Clinical Laboratory Improvement Amendments (https://www.cms.gov/Regulationsand-Guidance/Legislation/CLIA) for CDC use for diagnosis of SARS-CoV-2 from respiratory clinical specimens. On January 20, 2020, the CDC rRT-PCR panel confirmed an early case of COVID-19 in the United States (6). The US Food and Drug Administration issued an Emergency Use Authorization to enable emergency use of the CDC rRT-PCR panel as an in vitro diagnostic test for SARS-CoV-2 (https:/ / www.fda.gov/news-events/press-announcements/ fda-takes-significant-step-coronavirus-responseefforts-issues-emergency-use-authorization-first). From January 18 through February 27, as part of the COVID-19 response, CDC tested 2,923 specimens from 998 persons for SARS-CoV-2.

As of April 22, $\approx 2,400,000$ confirmed COVID-19 cases and $\approx 169,000$ associated deaths had been identified globally, including $\approx 770,000$ cases and $\approx 37,000$ deaths in the United States (7). We describe the design and validation of the CDC rRT-PCR panel and present comprehensive data on its performance with 
multiple specimen types and clinical specimens tested during the early CDC COVID-19 response.

\section{Materials and Methods}

\section{SARS-CoV-2 Cultured Virus and Other Respiratory Pathogens}

SARS-CoV-2 was isolated in Vero cells from a respiratory specimen from an early US COVID-19 patient (8). We measured infectious virus titer of virus stock by $50 \%$ tissue culture infectious dose $\left(\mathrm{TCID}_{50}\right)(2.01 \times$ $10^{6} \mathrm{TCID}_{50} / \mathrm{mL}$ ) and inactivated the virus by gamma irradiation. The inactivated stock virus was used as reference material for assay evaluation. Cell culture stocks or clinical specimens containing other respiratory viruses/bacteria were used to evaluate assay specificity. Ten nasopharyngeal swab samples that had been collected in 2018 (before COVID-19) and were negative for respiratory viruses were also available for assay specificity evaluation.

\section{Clinical Specimens}

We used the rRT-PCR panel for SARS-CoV-2 to test 2,923 clinical specimens collected from January 18 through February 27, 2020, from persons under investigation from 43 states and territories in the United States. Specimens included 2,437 specimens collected from 998 persons suspected to be infected who either met the initial definition of a COVID-19 person under investigation (9), were a close contact with a laboratory-confirmed COVID-19 case-patient, or had been repatriated to the United States from Wuhan, China, or the Diamond Princess cruise ship from Japan; and 486 specimens that were serially collected over time from 28 persons with COVID-19 confirmed at CDC. Respiratory specimens $(90.2 \%)$ included nasopharyngeal swab samples $(n=1,220)$ and oropharyngeal swab samples $(n=1,208)$ in viral transport medium, nasal swab/wash samples $(n=7)$, sputum $(n=197)$, bronchoalveolar lavage fluid $(n=2)$, lung tissues $(n=2)$, tracheal aspirate $(n=1)$, and bronchial wash samples $(\mathrm{n}=1)$. Nonrespiratory specimens $(9.8 \%)$ included serum $(n=156)$, urine $(n=72)$, stool $(n=54)$, cerebrospinal fluid $(n=2)$, and pericardial fluid $(n=1)$.

\section{Specimen Processing and Nucleic Acid Extraction}

We extracted total nucleic acid from $120 \mu \mathrm{L}$ of respiratory specimens by using the EZ1 DSP Virus Kit (QIAGEN, https://www.qiagen.com) following the manufacturer's instructions and collected $120 \mu \mathrm{L}$ elution volumes. We processed sputum specimens by adding equal volumes of $10 \mathrm{mM}$ of freshly prepared No-Weigh Thermo Scientific Pierce dithiothreitol
(Thermo Fisher Scientific, https://www.thermofisher.com) and incubating them at room temperature for 30 min with intermittent mixing or until the specimens were sufficiently liquefied for extraction. We processed stool specimens by preparing $10 \%$ suspensions by adding $100 \mu \mathrm{L}$ of liquid stool or $\approx 100 \mathrm{mg}$ of solid stool to $900 \mu \mathrm{L}$ of phosphate-buffered saline, pH 7.4 (Thermo Fisher Scientific), pulse vortexing for $30 \mathrm{~s}$, and centrifuging at $4,000 \times \mathrm{g}$ for $10 \mathrm{~min}$ at $4^{\circ} \mathrm{C}$. We then carefully removed the clarified supernatant for extraction. To demonstrate successful nucleic acid recovery and reagent integrity, we extracted human specimen control consisting of cultured A549 cells concurrently with the test specimens as a procedural control. We either tested extracts immediately or stored them at $\leq-70^{\circ} \mathrm{C}$ until use.

\section{Primers and Probes}

We aligned the $\mathrm{N}$ gene sequence from the publicly available SARS-CoV-2 genome (GenBank accession no. MN908947) with other coronavirus sequences available from GenBank by using MAFFT version 7.450 implemented in Geneious Prime (Geneious Biologics, https://www.geneious.com). We designed multiple primer/probe sets targeting regions in the 5', middle, and $3^{\prime}$ regions of the $\mathrm{N}$ gene sequence with the aid of Primer Express software version 3.0.1 (Thermo Fisher Scientific). We selected 3 candidate gene regions, designated N1, N2, and N3, for further study (Table 1). N1 and N2 were designed to specifically detect SARS-CoV-2, and N3 was designed to universally detect all currently recognized clade 2 and 3 viruses within the subgenus Sarbecovirus (4), including SARS-CoV-2, SARS-CoV, and bat- and civet-SARS-like CoVs. BLASTn (http://www.ncbi. nlm.nih.gov/blast/Blast.cgi) analysis demonstrated no major combined similarity of primers and probes of each assay with other coronaviruses (OC43, 229E, HKU1, NL63, and Middle East respiratory syndrome coronavirus [MERS-CoV]) or microflora of humans that would potentially yield false-positive results. We synthesized all primers and probes by using standard phosphoramidite chemistry techniques at the CDC Biotechnology Core Facility. We labeled hydrolysis probes at the $5^{\prime}$ end with 6-carboxy-fluorescein (FAM) and at the 3' end with Black Hole Quencher 1 (Biosearch Technologies, https://www.biosearchtech.com).

\section{In Vitro RNA Transcript and Viral Template Control}

Double-stranded DNA containing a 5'-T7 RNA polymerase promoter sequence (TAATACGACTCACTATAGGG) and the SARS-CoV-2 complete $\mathrm{N}$ gene 
Table 1. Assay primer/probe sequences for the US CDC rRT-PCR panel for detection of SARS-CoV-2*

\begin{tabular}{|c|c|c|c|c|c|c|}
\hline Assay & Genome target & $\begin{array}{l}\text { Genome } \\
\text { location }\end{array}$ & $\begin{array}{c}\text { Primers and } \\
\text { probes } \dagger\end{array}$ & Sequence, $5^{\prime} \rightarrow 3^{\prime}$ & $\begin{array}{l}\text { Amplicon } \\
\text { size, bp }\end{array}$ & Assay use \\
\hline N1 & $\begin{array}{l}\text { Nucleocapsid } \\
\text { gene }\end{array}$ & $\begin{array}{l}28303-28322 \ddagger \\
28374-28351 \ddagger \\
28325-28348 \ddagger\end{array}$ & $\begin{array}{l}\text { Forward primer } \\
\text { Reverse primer } \\
\text { Probe }\end{array}$ & $\begin{array}{c}\text { GACCCCAAAATCAGCGAAAT } \\
\text { TCTGGTTACTGCCAGTTGAATCTG } \\
\text { ACCCCGCATTACGTTTGGTGGACC }\end{array}$ & 73 & SARS-CoV-2 \\
\hline N2 & $\begin{array}{l}\text { Nucleocapsid } \\
\text { gene }\end{array}$ & $\begin{array}{l}29180-29199 \ddagger \\
29246-29228 \ddagger \\
29204-29226 \ddagger\end{array}$ & $\begin{array}{l}\text { Forward primer } \\
\text { Reverse primer } \\
\text { Probe }\end{array}$ & $\begin{array}{l}\text { TTACAAACATTGGCCGCAAA } \\
\text { GCGCGACATTCCGAAGAA } \\
\text { ACAATTTGCCCCCAGCGCTTCAG }\end{array}$ & 67 & SARS-CoV-2 \\
\hline N3 & $\begin{array}{l}\text { Nucleocapsid } \\
\text { gene }\end{array}$ & $\begin{array}{l}28697-28718 \ddagger \\
28768-28748 \ddagger \\
28720-28743 \ddagger\end{array}$ & $\begin{array}{l}\text { Forward primer } \\
\text { Reverse primer } \\
\text { Probe }\end{array}$ & $\begin{array}{l}\text { GGGAGCCTTGAATACACCAAAA } \\
\text { TGTAGCACGATTGCAGCATTG } \\
\text { AYCACATTGGCACCCGCAATCCTG }\end{array}$ & 72 & $\begin{array}{l}\text { SARS-CoV-2, } \\
\text { SARS-CoV, and } \\
\text { other } \\
\text { Sarbecoviruses } \$\end{array}$ \\
\hline RPT & $\begin{array}{c}\text { Human RNase } \\
\text { P gene }\end{array}$ & $\begin{array}{c}50-68 \# \\
114-95 \# \\
71-93 \# \\
\end{array}$ & $\begin{array}{c}\text { Forward primer } \\
\text { Reverse primer } \\
\text { Probe }\end{array}$ & $\begin{array}{c}\text { AGATTTGGACCTGCGAGCG } \\
\text { GAGCGGCTGTCTCCACAAGT } \\
\text { TTCTGACCTGAAGGCTCTGCGCG }\end{array}$ & 65 & $\begin{array}{l}\text { Sample quality } \\
\text { control }\end{array}$ \\
\hline \multicolumn{7}{|c|}{$\begin{array}{l}\text { *CDC, Centers for Disease Control and Prevention; N, nucleocapsid protein gene; } \\
\text { PCR; SARS-CoV-2, severe acute respiratory coronavirus } 2 \text {. } \\
\text { †Probes labeled at the 5'-end with the reporter molecule 6-carboxyfluorescein (FAI } \\
\text { Technologies Inc., https://www.biosearchtech.com). } \\
\text { †Nucleotide numbering based on SARS-CoV-2 (accession no. MN908947). } \\
\text { §Bat- and civet-SARS-like coronaviruses. } \\
\text { TPrimer/probe sequences from (10). } \\
\text { \#Nucleotide numbering based on human RP mRNA (accession no. NM_006413). }\end{array}$} \\
\hline
\end{tabular}

sequence was synthesized by Integrated DNA Technologies (https:/ / www.idtdna.com). We transcribed the DNA by using the MEGAscript T7 Transcription Kit (Thermo Fisher Scientific). The RNA transcripts were purified by using the MEGAclear Transcription Clean-Up Kit (Thermo Fisher Scientific) and quantified with a Qubit fluorometer by using a Qubit RNA HS Assay Kit (Thermo Fisher Scientific). We used the RNA transcript for subsequent assay evaluation and positive template control.

\section{rRT-PCR Assay}

We performed all rRT-PCR testing by using the TaqPath 1-Step RT-qPCR Master Mix, CG (Thermo Fisher Scientific). Each $20-\mu \mathrm{L}$ reaction contained $5 \mu \mathrm{L}$ of $4 \mathrm{X}$ Master Mix (Thermo Fisher Scientific), $0.5 \mu \mathrm{L}$ of 5 $\mu \mathrm{mol} / \mathrm{L}$ probe, $0.5 \mu \mathrm{L}$ each of $20 \mu \mathrm{mol} / \mathrm{L}$ forward and reverse primers, $8.5 \mu \mathrm{L}$ of nuclease-free water, and 5 $\mu \mathrm{L}$ of nucleic acid extract. We conducted amplification in 96-well plates on an Applied Biosystems 7500 Fast Dx Real-Time PCR Instrument (Thermo Fisher Scientific). Thermocycling conditions consisted of 2 min at $25^{\circ} \mathrm{C}$ for uracil-DNA glycosylase incubation, $15 \mathrm{~min}$ at $50^{\circ} \mathrm{C}$ for reverse transcription, $2 \mathrm{~min}$ at $95^{\circ} \mathrm{C}$ for activation of the Taq enzyme, and 45 cycles of 3 $\mathrm{s}$ at $95^{\circ} \mathrm{C}$ and $30 \mathrm{~s}$ at $55^{\circ} \mathrm{C}$. We set the threshold in the middle of exponential amplification phase in log view. A positive test result was defined as an exponential fluorescent curve that crossed the threshold within 40 cycles (cycle threshold $\left[C_{t}\right]<40$ ).

\section{Test Algorithm}

For routine specimen testing, we ran all 3 SARS$\mathrm{CoV}-2$ assays simultaneously along with the human ribonuclease $\mathrm{P}$ gene $(\mathrm{RP})$ assay to monitor nucleic acid extraction, specimen quality, and presence of reaction inhibitors. To monitor assay performance, we included positive template controls, no-template controls, and human specimen controls in all runs. When all controls exhibited expected performance, we considered a specimen to be positive for SARS$\mathrm{CoV}-2$ if all assay amplification curves crossed the threshold line within 40 cycles $\left(C_{t}<40\right)$. If all 3 assay results were negative, the test result was reported as negative. If all 3 assay results were not positive, an inconclusive test result was recorded and retesting was required. If both initial and retest results were inconclusive, the final result was reported as inconclusive.

\section{Results}

\section{Assay Efficiency}

We prepared serial 10-fold dilutions of quantified RNA transcript in $10 \mathrm{mmol} / \mathrm{L}$ Tris- $\mathrm{HCl}$ buffer containing $50 \mathrm{ng} / \mu \mathrm{L}$ of yeast tRNA (Thermo Fisher Scientific) and tested them by each assay. A linear amplification was achieved over an 8-log dynamic range from 5 to $5 \times 10^{7}$ copies/reaction for all 3 assays; calculated efficiency ranged from $99.4 \%$ to $102.6 \%$ (Figure 1).

\section{Analytical Sensitivity (Limits of Detection)}

\section{SARS-CoV-2 RNA Transcripts}

We tested serial 2-fold dilutions of quantified RNA transcript prepared in buffer as above by each assay in 24 replicates/dilution. The highest dilution of transcript at which all replicates were positive was 

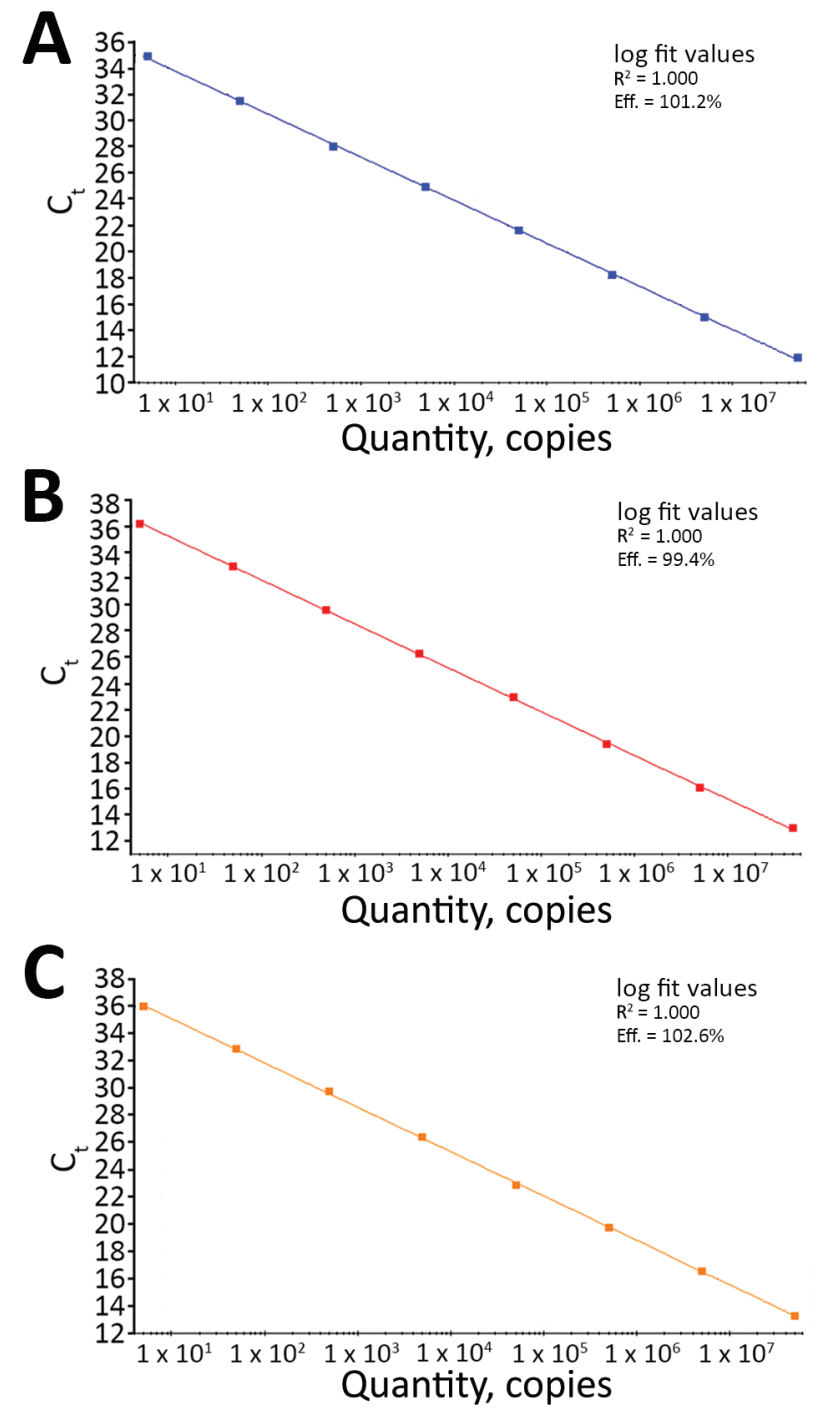

Figure 1. Linear regression analysis of serial 10 -fold dilutions of synthetic RNA transcripts of the nucleocapsid gene $(N)$ ranging from 5 to $5 \times 10^{7}$ copies/reaction tested by the N1 (A), N2 (B), and N3 (C) assays in the US Centers for Disease Control and Prevention real-time reverse transcription PCR panel for detection of severe acute respiratory syndrome coronavirus 2 . For each assay, $\mathrm{R}^{2}$ indicates calculated linear correlation coefficients and eff. indicates amplification efficiencies. $\mathrm{C}_{\mathrm{t}}$, cycle threshold.

defined as the limit of detection (LoD) for each assay. The LoDs for all assays were 5 RNA transcript copies/reaction (Table 2), which is consistent with that previously demonstrated (11).

\section{SARS-CoV-2 Genomic RNA}

We tested serial half-log dilutions of SARS-CoV-2 RNA extracted from inactivated cultured virus and prepared in buffer as above in triplicate by each assay (Table 3 ). For all 3 assays, the LoD was $\approx 1 \times 10^{-1.5}$ $\mathrm{TCID}_{50} / \mathrm{mL}$.
Table 2. Limits of detection of the US CDC rRT-PCR panel for detection of SARS-CoV-2 with RNA transcripts*

\begin{tabular}{lccc}
\hline Copies/ & \multicolumn{3}{c}{ No. positive tests/no. (\%) reaction replicates } \\
\cline { 2 - 4 } reaction & $\mathrm{N} 1$ & $\mathrm{~N} 2$ & $\mathrm{~N} 3$ \\
\hline 20 & $24 / 24(100)$ & $24 / 24(100)$ & $24 / 24(100)$ \\
10 & $24 / 24(100)$ & $24 / 24(100)$ & $24 / 24(100)$ \\
5 & $24 / 24(100)$ & $24 / 24(100)$ & $24 / 24(100)$ \\
2.5 & $23 / 24(95.8)$ & $16 / 24(66.7)$ & $15 / 24(62.5)$ \\
1.25 & $15 / 24(62.5)$ & $8 / 24(33.3)$ & $3 / 24(12.5)$ \\
\hline${ }^{*}$ CDC, Centers for Disease Control and Prevention; N, nucleocapsid \\
protein gene; rRT-PCR, real-time reverse transcription PCR; SARS-CoV- \\
2, severe acute respiratory coronavirus 2.
\end{tabular}

SARS-CoV-2 Spiked in Different Clinical Matrices

Serial half-log dilutions of SARS-CoV-2 were spiked in different specimen matrices contrived from pooled human clinical specimens: 10 serum samples, 10 nasopharyngeal swab samples, 10 oropharyngeal swab samples, 10 sputum samples, and 10 stool suspensions (prepared as $10 \%$ suspensions). The LoDs for all assays ranged from $1.0 \times 10^{-1.5}$ to $1.0 \times 10^{-1} \mathrm{TCID}_{50} / \mathrm{mL}$ across all specimen matrices (Table 4). Negative results were obtained for all 3 assays with all pooled negative specimen matrices.

\section{Assay Reproducibility}

We evaluated assay reproducibility by using 3 contrived respiratory specimens constructed from pooled nasopharyngeal swabs and spiked with high $\left(1.0 \times 10^{3} \mathrm{TCID}_{50} / \mathrm{mL}\right)$, moderate $\left(1.0 \times 10^{1}\right.$ $\left.\mathrm{TCID}_{50} / \mathrm{mL}\right)$, and low $\left(1.0 \times 10^{-1} \mathrm{TCID}_{50} / \mathrm{mL}\right)$ concentrations of virus. We extracted the contrived specimens, and tested them in triplicate against each assay on 3 different days. Interassay variation was low for all assays (coefficient of variation range for $\mathrm{N} 1,1.8 \%-3.7 \%$; N2, $2.3 \%-2.8 \%$; N3, $1.1 \%-1.3 \%$; RP, $0.9 \%-1.5 \%$ ) (Table 5).

\section{Analytical Specificity}

\section{In Silico Analysis Against Available SARS-CoV-2}

\section{Genome Sequences}

We evaluated the primer/probe sequences of the 3 assays against 7,158 genome sequences available from the Global Initiative on Sharing All Influenza Data (GISAID, https://www.gisaid.org) as of April 14,2020 . Nucleotide mismatches in the primer/probe regions with frequency $\geq 0.1 \%$ were sporadic among viruses (Table 6). Except for 1 nucleotide mismatch with frequency $>1 \%(1.55 \%)$ at the eighth position of the N3 forward primer, frequency of all other mismatches was $<1 \%$. These nucleotide mismatches would not be expected to affect reaction performance. No viruses were found to have $>1$ mismatch in any primer/probe region. 
Table 3. Limits of detection of the US CDC rRT-PCR panel for detection of SARS-CoV-2 with extracted SARS-CoV-2 virus RNA*

\begin{tabular}{|c|c|c|c|c|c|c|c|c|c|c|c|c|}
\hline \multirow{2}{*}{$\begin{array}{l}\text { Virus } \\
\text { concentration, } \\
\text { TCID }_{50}\end{array}$} & \multicolumn{4}{|c|}{$\mathrm{N} 1 \mathrm{C}_{\mathrm{t}}$} & \multicolumn{4}{|c|}{$\mathrm{N} 2 \mathrm{C}_{\mathrm{t}}$} & \multicolumn{4}{|c|}{ N3 $C_{t}$} \\
\hline & Test 1 & Test 2 & Test 3 & Call rate & Test 1 & Test 2 & Test 3 & Call rate & Test 1 & Test 2 & Test 3 & Call rate \\
\hline $1 \times 10^{0.5}$ & 27.5 & 27.1 & 27.4 & $3 / 3$ & 29.2 & 28.9 & 28.7 & $3 / 3$ & 28.3 & 28.3 & 28.2 & $3 / 3$ \\
\hline $1 \times 10^{0}$ & 30.9 & 29.4 & 29.9 & $3 / 3$ & 31.2 & 31.1 & 31.1 & $3 / 3$ & 30.0 & 30.0 & 30.0 & $3 / 3$ \\
\hline $1 \times 10^{-0.5}$ & 30.7 & 30.9 & 31.1 & $3 / 3$ & 33.0 & 32.7 & 32.3 & $3 / 3$ & 31.4 & 31.4 & 32.5 & $3 / 3$ \\
\hline $1 \times 10^{-1}$ & 33.0 & 32.4 & 32.9 & $3 / 3$ & 34.4 & 34.3 & 34.7 & $3 / 3$ & 34.6 & 32.3 & 33.3 & $3 / 3$ \\
\hline $1 \times 10^{-1.5}$ & 34.4 & 33.6 & 35.6 & $3 / 3$ & 36.3 & 36.1 & 37.6 & $3 / 3$ & 35.4 & 35.8 & 35.6 & $3 / 3$ \\
\hline $1 \times 10^{-2}$ & 37.2 & 36.1 & Neg & $2 / 3$ & 39.0 & Neg & Neg & $1 / 3$ & 36.1 & $\mathrm{Neg}$ & $\mathrm{Neg}$ & $1 / 3$ \\
\hline $1 \times 10^{-2.5}$ & 36.2 & 36.3 & Neg & $2 / 3$ & 38.8 & 37.6 & Neg & $2 / 3$ & 37.1 & Neg & $\mathrm{Neg}$ & $1 / 3$ \\
\hline $1 \times 10^{-3}$ & $\mathrm{Neg}$ & $\mathrm{Neg}$ & Neg & $0 / 3$ & $\mathrm{Neg}$ & $\mathrm{Neg}$ & Neg & $0 / 3$ & $\mathrm{Neg}$ & $\mathrm{Neg}$ & $\mathrm{Neg}$ & $0 / 3$ \\
\hline
\end{tabular}

Cross-Reactivity with Other Respiratory Pathogens and Human Microbial Flora

We evaluated the specificity of the SARS-CoV-2 rRTPCR assay with purified nucleic acid obtained from a collection of respiratory pathogen isolates or positive clinical specimens, including human coronaviruses 229E, OC43, NL63, HKU1, SARS-CoV, and MERS-CoV (Table 7). We also tested 10 nasopharyngeal swabs samples collected in 2018 before COVID-19 was identified. Except for the N3 assay, which was reactive with SARS-CoV RNA as expected, we observed no false-positive results for any pathogens and specimens tested.

\section{Clinical Specimen Testing}

\section{Specimens from Persons with Suspected Cases}

Among the 2,437 clinical specimens collected from 998 persons with suspected cases for initial SARSCoV-2 diagnostic testing, 81 (3.32\%) specimens (42 nasopharyngeal, 33 oropharyngeal, 5 sputum, 1 BAL) collected from 46 persons with suspected cases were positive and 2,355 (96.64\%) specimens were negative (Table 8 ). We did not detect SARS-CoV-2 RNA in any of the 74 serum and 10 urine specimens tested.

\section{Serially Collected Specimens from Persons with Laboratory-Confirmed COVID-19}

Of 486 specimens serially collected from 28 persons with laboratory-confirmed COVID-19, results were SARS-CoV-2 positive for $142(29.22 \%)$ samples (60 nasopharyngeal, 42 oropharyngeal, 13 sputum, 1 tracheal aspirate, 22 stool, and 4 serum) (Table 8). We detected SARS-CoV-2 RNA in serum of 2 of 15 persons with laboratory-confirmed COVID-19 for whom serum was available for testing. For 1 of those casepatients, serum was collected 14 days after symptom onset and tested positive. For the other case-patient, a total of 10 serum samples were collected. Of those, specimens collected on days 9, 11, and 13 were positive; specimens collected on days $3,19,22,25$, and 28 were negative; and specimens collected on days 6 and 16 had inconclusive results. A total of 22 stool specimens collected from 7 case-patients were positive. We detected no SARS-CoV-2 RNA in any of the 62 urine specimens collected.

\section{Specimens with Positive Results According to the SARS-CoV-2 rRT-PCR Assay}

Of the 223 clinical specimens with positive results by all 3 rRT-PCR assays, $C_{t}$ values obtained by the N1, $\mathrm{N} 2$, and N3 assays correlated well with each other $\left(\mathrm{N} 1\right.$ vs. N2, $\mathrm{R}^{2}=0.94 ; \mathrm{N} 1$ vs. N3, $\mathrm{R}^{2}=0.97 ; \mathrm{N} 2$ vs. N3, $\mathrm{R}^{2}=0.96$ ) (Figure 2). Among the 71 pairs of nasopharyngeal and oropharyngeal specimens collected simultaneously from the 46 persons with suspected cases or from persons with laboratory-confirmed COVID-19 and any positive nasopharyngeal/ oropharyngeal specimen, both nasopharyngeal and oropharyngeal samples were positive for 31 (43.67\%); nasopharyngeal was positive but oropharyngeal was negative for 24 (33.80\%); oropharyngeal was positive but nasopharyngeal was negative for $7(9.86 \%)$; nasopharyngeal was positive but oropharyngeal was inconclusive for 5 (7.04\%); and oropharyngeal was positive but nasopharyngeal was inconclusive for $4(5.63 \%)$.

\section{Inconclusive SARS-CoV-2 rRT-PCR Results}

Inconclusive results were obtained for $40(1.37 \%)$ of 2,923 specimens tested, including $1(0.04 \%)$ of 2,437 , from a person with a suspected case at initial testing, and $39(8.02 \%)$ of 486 specimens collected for follow-up investigation from persons with laboratory-confirmed COVID-19. All specimens with inconclusive results had $C_{t}$ values $>35$ (Table 9). Of these, $35(87.5 \%)$ specimens were collected $\geq 7$ days after symptom onset. Times from symptom onset to collection were unknown for the other 5 $(12.5 \%)$ specimens. 
Quality Control Data

Among 185 no-template controls and 219 human specimen controls included with specimen testing, negative results were obtained for all $(100 \%)$ controls for N1, N2, and N3 assays and expected RP values were observed for human specimen controls. $\mathrm{C}_{t}$ values obtained from positive template control of 185 runs were in the expected range (data not shown).

Table 4. Performance of the US CDC rRT-PCR panel for detection of SARS-CoV-2 with various specimen matrices spiked with SARSCoV-2*

\begin{tabular}{|c|c|c|c|c|c|c|c|c|c|c|c|c|c|c|c|c|}
\hline \multirow[b]{2}{*}{$\begin{array}{l}\text { Virus titer, } \\
\text { TCID }_{50} \dagger\end{array}$} & \multicolumn{4}{|c|}{$\mathrm{N} 1 \mathrm{C}_{\mathrm{t}}$} & \multicolumn{4}{|c|}{$\mathrm{N} 2 \mathrm{C}_{\mathrm{t}}$} & \multicolumn{4}{|c|}{ N3 $C_{t}$} & \multicolumn{4}{|c|}{$\mathrm{RP} \mathrm{C}_{\mathrm{t}}$} \\
\hline & $\begin{array}{c}\text { Test } \\
1 \\
\end{array}$ & $\begin{array}{c}\text { Test } \\
2 \\
\end{array}$ & $\begin{array}{c}\text { Test } \\
3\end{array}$ & $\begin{array}{l}\text { Call } \\
\text { rate }\end{array}$ & $\begin{array}{c}\text { Test } \\
1 \\
\end{array}$ & $\begin{array}{c}\text { Test } \\
2 \\
\end{array}$ & $\begin{array}{c}\text { Test } \\
3\end{array}$ & $\begin{array}{l}\text { Call } \\
\text { rate }\end{array}$ & $\begin{array}{c}\text { Test } \\
1 \\
\end{array}$ & $\begin{array}{c}\text { Test } \\
2 \\
\end{array}$ & $\begin{array}{c}\text { Test } \\
3\end{array}$ & $\begin{array}{l}\text { Call } \\
\text { rate }\end{array}$ & $\begin{array}{c}\text { Test } \\
1 \\
\end{array}$ & $\begin{array}{c}\text { Test } \\
2 \\
\end{array}$ & $\begin{array}{c}\text { Test } \\
3\end{array}$ & $\begin{array}{l}\text { Call } \\
\text { rate }\end{array}$ \\
\hline \multicolumn{17}{|l|}{$1 \times 10^{0.5}$} \\
\hline NP & 30.4 & 29.9 & 29.9 & $3 / 3$ & 30.3 & 30.5 & 30.5 & $3 / 3$ & 30.0 & 29.6 & 29.7 & $3 / 3$ & 26.0 & 26.1 & 26.1 & $3 / 3$ \\
\hline OP & 30.1 & 29.7 & 29.7 & $3 / 3$ & 30.7 & 30.8 & 30.5 & $3 / 3$ & 29.6 & 29.5 & 29.5 & $3 / 3$ & 30.0 & 30.3 & 30.2 & $3 / 3$ \\
\hline Sputum & 30.3 & 30.1 & 30.4 & $3 / 3$ & 31.2 & 31.5 & 31.7 & $3 / 3$ & 30.5 & 30.0 & 30.4 & $3 / 3$ & 24.9 & 24.8 & 25.1 & $3 / 3$ \\
\hline Serum & 30.1 & 29.7 & 29.8 & $3 / 3$ & 31.1 & 31.0 & 31.1 & $3 / 3$ & 29.8 & 29.8 & 29.6 & $3 / 3$ & 29.1 & 28.6 & 28.3 & $3 / 3$ \\
\hline Stool & 30.7 & 30.5 & 30.7 & $3 / 3$ & 31.7 & 31.9 & 31.7 & $3 / 3$ & 30.7 & 29.9 & 30.2 & $3 / 3$ & 34.9 & 35.1 & 35.7 & $3 / 3$ \\
\hline \multicolumn{17}{|l|}{$1 \times 10^{0}$} \\
\hline NP & 32.1 & 30.8 & 30.4 & $3 / 3$ & 32.3 & 32.0 & 31.6 & $3 / 3$ & 31.3 & 30.7 & 30.9 & $3 / 3$ & 24.5 & 24.2 & 25.0 & $3 / 3$ \\
\hline OP & 31.6 & 31.3 & 31.4 & $3 / 3$ & 32.8 & 32.3 & 32.2 & $3 / 3$ & 30.8 & 31.3 & 31.1 & $3 / 3$ & 29.3 & 29.2 & 29.5 & $3 / 3$ \\
\hline Sputum & 32.0 & 32.0 & 31.8 & $3 / 3$ & 33.1 & 32.9 & 32.7 & $3 / 3$ & 31.7 & 31.4 & 32.1 & $3 / 3$ & 24.3 & 24.3 & 24.6 & $3 / 3$ \\
\hline Serum & 32.2 & 30.8 & 31.4 & $3 / 3$ & 32.4 & 32.6 & 33.1 & $3 / 3$ & 31.2 & 31.3 & 31.3 & $3 / 3$ & 28.1 & 28.2 & 27.5 & $3 / 3$ \\
\hline Stool & 32.1 & 32.3 & 32.0 & $3 / 3$ & 33.6 & 33.9 & 33.5 & $3 / 3$ & 32.1 & 32.0 & 32.1 & $3 / 3$ & 34.6 & 35.1 & 34.5 & $3 / 3$ \\
\hline \multicolumn{17}{|l|}{$1 \times 10^{-0.5}$} \\
\hline NP & 33.7 & 32.5 & 33.9 & $3 / 3$ & 34.1 & 33.9 & 35.5 & $3 / 3$ & 33.2 & 32.6 & 33.5 & $3 / 3$ & 25.3 & 25.4 & 25.5 & $3 / 3$ \\
\hline OP & 33.6 & 33.6 & 33.1 & $3 / 3$ & 34.4 & 34.4 & 34.6 & $3 / 3$ & 33.5 & 33.0 & 32.0 & $3 / 3$ & 29.2 & 29.4 & 29.6 & $3 / 3$ \\
\hline Sputum & 35.1 & 33.4 & 33.0 & $3 / 3$ & 35.0 & 34.2 & 34.8 & $3 / 3$ & 33.5 & 33.4 & 33.2 & $3 / 3$ & 24.0 & 24.2 & 24.3 & $3 / 3$ \\
\hline Serum & 33.4 & 32.2 & 33.3 & $3 / 3$ & 35.2 & 34.1 & 33.9 & $3 / 3$ & 32.7 & 32.7 & 33.1 & $3 / 3$ & 28.3 & 28.2 & 29.3 & $3 / 3$ \\
\hline Stool & 35.0 & 35.3 & 35.3 & $3 / 3$ & 36.2 & 36.4 & 35.3 & $3 / 3$ & 34.2 & 34.6 & 34.0 & $3 / 3$ & 33.4 & 36.2 & 35.0 & $3 / 3$ \\
\hline \multicolumn{17}{|l|}{$1 \times 10^{-1}$} \\
\hline NP & 33.9 & 34.0 & 34.6 & $3 / 3$ & 36.0 & 36.2 & 36.5 & $3 / 3$ & 34.1 & 34.3 & 35.1 & $3 / 3$ & 25.6 & 25.6 & 25.9 & $3 / 3$ \\
\hline OP & 33.4 & 33.3 & 33.6 & $3 / 3$ & 35.9 & 36.7 & 35.3 & $3 / 3$ & 34.5 & 34.3 & 35.1 & $3 / 3$ & 29.2 & 29.3 & 29.3 & $3 / 3$ \\
\hline Sputum & 35.2 & 35.0 & 36.2 & $3 / 3$ & 36.8 & 36.8 & 35.3 & $3 / 3$ & 35.3 & 35.2 & 35.1 & $3 / 3$ & 24.1 & 24.1 & 24.3 & $3 / 3$ \\
\hline Serum & 37.5 & 35.3 & 34.8 & $3 / 3$ & 36.4 & 37.2 & 36.3 & $3 / 3$ & 35.2 & 33.7 & 34.3 & $3 / 3$ & 28.3 & 28.3 & 28.6 & $3 / 3$ \\
\hline Stool & 36.1 & 35.8 & 36.0 & $3 / 3$ & 37.3 & 37.9 & 38.1 & $3 / 3$ & 35.8 & 35.6 & 34.7 & $3 / 3$ & 34.1 & 33.9 & 34.2 & $3 / 3$ \\
\hline \multicolumn{17}{|l|}{$1 \times 10^{-1.5}$} \\
\hline NP & 35.6 & 36.8 & 35.9 & $3 / 3$ & 39.9 & 36.8 & 37.6 & $3 / 3$ & 36.7 & 35.1 & 35.7 & $3 / 3$ & 26.1 & 26.3 & 26.6 & $3 / 3$ \\
\hline OP & 36.2 & 35.2 & $\mathrm{Neg}$ & $2 / 3$ & 36.8 & 38.0 & $\mathrm{Neg}$ & $2 / 3$ & $\mathrm{Neg}$ & $\mathrm{Neg}$ & $\mathrm{Neg}$ & $0 / 3$ & 29.3 & 29.3 & 29.6 & $3 / 3$ \\
\hline Sputum & 36.9 & 36.3 & $\mathrm{Neg}$ & $2 / 3$ & 39.1 & 39.5 & 38.4 & $3 / 3$ & 35.8 & 38.2 & $\mathrm{Neg}$ & $2 / 3$ & 23.9 & 24.2 & 24.2 & $3 / 3$ \\
\hline Serum & 36.8 & 36.5 & 36.4 & $3 / 3$ & 38.4 & 39.1 & 36.9 & $3 / 3$ & 35.6 & 36.2 & $\mathrm{Neg}$ & $2 / 3$ & 27.9 & 28.2 & 27.4 & $3 / 3$ \\
\hline Stool & $\mathrm{Neg}$ & $\mathrm{Neg}$ & $\mathrm{Neg}$ & $0 / 3$ & 39.2 & 38.1 & 37.5 & $3 / 3$ & 35.5 & 38.1 & 38.0 & $3 / 3$ & 34.2 & 33.3 & 35.6 & $3 / 3$ \\
\hline \multicolumn{17}{|l|}{$1 \times 10^{-2}$} \\
\hline NP & $\mathrm{Neg}$ & Neg & $\mathrm{Neg}$ & $0 / 3$ & 39.4 & $\mathrm{Neg}$ & $\mathrm{Neg}$ & $1 / 3$ & Neg & $\mathrm{Neg}$ & Neg & $0 / 3$ & 25.5 & 25.7 & 25.8 & $3 / 3$ \\
\hline OP & $\mathrm{Neg}$ & $\mathrm{Neg}$ & $\mathrm{Neg}$ & $0 / 3$ & 38.5 & 38.0 & $\mathrm{Neg}$ & $2 / 3$ & 37.1 & $\mathrm{Neg}$ & $\mathrm{Neg}$ & $1 / 3$ & 29.4 & 29.3 & 29.4 & $3 / 3$ \\
\hline Sputum & 36.1 & $\mathrm{Neg}$ & $\mathrm{Neg}$ & $1 / 3$ & 38.2 & 38.5 & $\mathrm{Neg}$ & $2 / 3$ & 37.1 & 37.5 & $\mathrm{Neg}$ & $2 / 3$ & 24.0 & 24.0 & 24.1 & $3 / 3$ \\
\hline Serum & 37.5 & $\mathrm{Neg}$ & $\mathrm{Neg}$ & $1 / 3$ & 39.9 & $\mathrm{Neg}$ & $\mathrm{Neg}$ & $1 / 3$ & 38.9 & $\mathrm{Neg}$ & $\mathrm{Neg}$ & $1 / 3$ & 28.2 & 27.9 & 27.2 & $3 / 3$ \\
\hline Stool & $\mathrm{Neg}$ & $\mathrm{Neg}$ & Neg & $0 / 3$ & 39.1 & $\mathrm{Neg}$ & $\mathrm{Neg}$ & $1 / 3$ & 38.1 & Neg & $\mathrm{Neg}$ & $1 / 3$ & 33.5 & 35.1 & 34.6 & $3 / 3$ \\
\hline \multicolumn{17}{|l|}{$1 \times 10^{-2.5}$} \\
\hline NP & 36.2 & $\mathrm{Neg}$ & $\mathrm{Neg}$ & $1 / 3$ & 38.9 & $\mathrm{Neg}$ & $\mathrm{Neg}$ & $1 / 3$ & Neg & $\mathrm{Neg}$ & $\mathrm{Neg}$ & $0 / 3$ & 26.3 & 26.5 & 26.6 & $3 / 3$ \\
\hline OP & $\mathrm{Neg}$ & $\mathrm{Neg}$ & $\mathrm{Neg}$ & $0 / 3$ & $\mathrm{Neg}$ & $\mathrm{Neg}$ & $\mathrm{Neg}$ & $0 / 3$ & Neg & $\mathrm{Neg}$ & $\mathrm{Neg}$ & $0 / 3$ & 29.0 & 29.2 & 29.2 & $3 / 3$ \\
\hline Sputum & 37.4 & Neg & Neg & $1 / 3$ & Neg & Neg & Neg & $0 / 3$ & 36.7 & Neg & $\mathrm{Neg}$ & $1 / 3$ & 24.0 & 24.2 & 24.4 & $3 / 3$ \\
\hline Serum & 36.4 & Neg & Neg & $1 / 3$ & 38.4 & Neg & Neg & $1 / 3$ & $\mathrm{Neg}$ & Neg & $\mathrm{Neg}$ & $0 / 3$ & 28.1 & 28.2 & 27.2 & $3 / 3$ \\
\hline Stool & 37.6 & $\mathrm{Neg}$ & $\mathrm{Neg}$ & $1 / 3$ & $\mathrm{Neg}$ & $\mathrm{Neg}$ & $\mathrm{Neg}$ & $0 / 3$ & $\mathrm{Neg}$ & $\mathrm{Neg}$ & $\mathrm{Neg}$ & $0 / 3$ & 33.4 & 34.1 & 35.5 & $3 / 3$ \\
\hline \multicolumn{17}{|l|}{$1 \times 10^{-3}$} \\
\hline NP & $\mathrm{Neg}$ & $\mathrm{Neg}$ & $\mathrm{Neg}$ & $0 / 3$ & $\mathrm{Neg}$ & $\mathrm{Neg}$ & $\mathrm{Neg}$ & $0 / 3$ & $\mathrm{Neg}$ & $\mathrm{Neg}$ & $\mathrm{Neg}$ & $0 / 3$ & 26.8 & 26.7 & 27.0 & $3 / 3$ \\
\hline OP & $\mathrm{Neg}$ & $\mathrm{Neg}$ & Neg & $0 / 3$ & Neg & Neg & Neg & $0 / 3$ & $\mathrm{Neg}$ & Neg & $\mathrm{Neg}$ & $0 / 3$ & 29.2 & 29.4 & 29.1 & $3 / 3$ \\
\hline Sputum & $\mathrm{Neg}$ & $\mathrm{Neg}$ & Neg & $0 / 3$ & Neg & Neg & Neg & $0 / 3$ & $\mathrm{Neg}$ & Neg & $\mathrm{Neg}$ & $0 / 3$ & 23.9 & 24.1 & 24.3 & $3 / 3$ \\
\hline Serum & $\mathrm{Neg}$ & $\mathrm{Neg}$ & Neg & $0 / 3$ & Neg & Neg & Neg & $0 / 3$ & $\mathrm{Neg}$ & Neg & $\mathrm{Neg}$ & $0 / 3$ & 28.2 & 28.3 & 27.9 & $3 / 3$ \\
\hline Stool & $\mathrm{Neg}$ & $\mathrm{Neg}$ & Neg & $0 / 3$ & $\mathrm{Neg}$ & $\mathrm{Neg}$ & $\mathrm{Neg}$ & $0 / 3$ & $\mathrm{Neg}$ & $\mathrm{Neg}$ & $\mathrm{Neg}$ & $0 / 3$ & 34.1 & 35.0 & 35.0 & $3 / 3$ \\
\hline 0 & & & & & & & & & & & & & & & & \\
\hline NP & $\mathrm{Neg}$ & $\mathrm{Neg}$ & $\mathrm{Neg}$ & $0 / 3$ & $\mathrm{Neg}$ & $\mathrm{Neg}$ & $\mathrm{Neg}$ & $0 / 3$ & Neg & $\mathrm{Neg}$ & $\mathrm{Neg}$ & $0 / 3$ & 25.0 & 25.2 & 24.8 & $3 / 3$ \\
\hline OP & $\mathrm{Neg}$ & $\mathrm{Neg}$ & $\mathrm{Neg}$ & $0 / 3$ & $\mathrm{Neg}$ & $\mathrm{Neg}$ & $\mathrm{Neg}$ & $0 / 3$ & $\mathrm{Neg}$ & $\mathrm{Neg}$ & $\mathrm{Neg}$ & $0 / 3$ & 28.6 & 28.3 & 28.5 & $3 / 3$ \\
\hline Sputum & $\mathrm{Neg}$ & $\mathrm{Neg}$ & $\mathrm{Neg}$ & $0 / 3$ & $\mathrm{Neg}$ & $\mathrm{Neg}$ & $\mathrm{Neg}$ & $0 / 3$ & $\mathrm{Neg}$ & $\mathrm{Neg}$ & $\mathrm{Neg}$ & $0 / 3$ & 23.1 & 23.0 & 23.1 & $3 / 3$ \\
\hline Serum & $\mathrm{Neg}$ & $\mathrm{Neg}$ & $\mathrm{Neg}$ & $0 / 3$ & $\mathrm{Neg}$ & $\mathrm{Neg}$ & $\mathrm{Neg}$ & $0 / 3$ & $\mathrm{Neg}$ & $\mathrm{Neg}$ & $\mathrm{Neg}$ & $0 / 3$ & 27.6 & 27.8 & 27.7 & $3 / 3$ \\
\hline Stool & $\mathrm{Neg}$ & $\mathrm{Neg}$ & $\mathrm{Neg}$ & $0 / 3$ & $\mathrm{Neg}$ & $\mathrm{Neg}$ & $\mathrm{Neg}$ & $0 / 3$ & $\mathrm{Neg}$ & $\mathrm{Neg}$ & $\mathrm{Neg}$ & $0 / 3$ & 33.5 & 33.8 & 33.2 & $3 / 3$ \\
\hline
\end{tabular}


Table 5. Reproducibility of the US CDC rRT-PCR panel for detection of SARS-CoV-2 with respiratory specimen matrix spiked with SARS-CoV-2*

\begin{tabular}{|c|c|c|c|c|c|c|c|c|c|c|c|c|}
\hline \multirow[b]{2}{*}{ Virus titer, TCID 50} & \multicolumn{3}{|c|}{$\mathrm{N} 1 \mathrm{C}_{t}$} & \multicolumn{3}{|c|}{$\mathrm{N} 2 \mathrm{C}_{\mathrm{t}}$} & \multicolumn{3}{|c|}{ N3 $C_{t}$} & \multicolumn{3}{|c|}{$\mathrm{RP}_{\mathrm{t}}$} \\
\hline & Test 1 & Test 2 & Test 3 & Test 1 & Test 2 & Test 3 & Test 1 & Test 2 & Test 3 & Test 1 & Test 2 & Test 3 \\
\hline \multicolumn{13}{|l|}{ Day 1} \\
\hline $1.0 \times 10^{3}$ & 21.1 & 21.1 & 21.0 & 21.5 & 21.2 & 21.5 & 21.0 & 21.1 & 21.1 & 26.0 & 25.9 & 26.1 \\
\hline $1.0 \times 10^{1}$ & 27.8 & 27.6 & 27.5 & 28.6 & 28.6 & 28.9 & 27.6 & 27.3 & 27.7 & 26.0 & 25.8 & 26.1 \\
\hline $1.0 \times 10^{-1}$ & 35.6 & 33.8 & 33.8 & 34.7 & 34.2 & 34.5 & 34.0 & 34.5 & 33.7 & 26.4 & 26.4 & 26.4 \\
\hline \multicolumn{13}{|l|}{ Day 2} \\
\hline $1.0 \times 10^{3}$ & 21.8 & 21.8 & 21.8 & 21.6 & 21.5 & 21.6 & 21.2 & 21.1 & 21.2 & 26.5 & 26.3 & 26.3 \\
\hline $1.0 \times 10^{1}$ & 28.4 & 28.3 & 28.5 & 29.4 & 29.3 & 29.0 & 28.1 & 28.0 & 28.1 & 26.7 & 26.7 & 26.67 \\
\hline $1.0 \times 10^{-1}$ & 37.6 & 35.7 & 34.0 & 36.0 & 34.7 & 34.9 & 34.1 & 33.8 & 34.5 & 26.8 & 26.3 & 26.2 \\
\hline \multicolumn{13}{|l|}{ Day 3} \\
\hline $1.0 \times 10^{3}$ & 20.8 & 20.7 & 20.8 & 20.6 & 20.4 & 20.6 & 20.7 & 20.6 & 20.7 & 26.8 & 26.7 & 26.9 \\
\hline $1.0 \times 10^{1}$ & 27.1 & 27.6 & 27.3 & 27.5 & 27.6 & 27.4 & 27.2 & 27.3 & 27.3 & 26.6 & 26.8 & 26.8 \\
\hline $1.0 \times 10^{-1}$ & 34.2 & 33.9 & 34.1 & 33.1 & 33.5 & 34.9 & 33.2 & 34.2 & 33.5 & 26.6 & 26.9 & 26.7 \\
\hline Summary results & Mean & SD & $\mathrm{CV}$ & Mean & SD & $\mathrm{CV}$ & Mean & SD & CV & Mean & SD & $\mathrm{CV}$ \\
\hline $1.0 \times 10^{3}$ & 21.2 & 0.5 & $2.2 \%$ & 21.2 & 0.5 & $2.3 \%$ & 21.0 & 0.2 & $1.1 \%$ & 26.4 & 0.4 & $1.4 \%$ \\
\hline $1.0 \times 10^{1}$ & 27.8 & 0.5 & $1.8 \%$ & 28.5 & 0.8 & $2.8 \%$ & 27.6 & 0.4 & $1.3 \%$ & 26.5 & 0.4 & $1.5 \%$ \\
\hline $1.0 \times 10^{-1}$ & 34.7 & 1.3 & $3.7 \%$ & 34.5 & 0.8 & $2.5 \%$ & 33.9 & 0.4 & $1.2 \%$ & 26.5 & 0.2 & $0.9 \%$ \\
\hline
\end{tabular}

*Specimen matrix constructed from combined nasopharyngeal swabs obtained from 10 persons. CDC, Centers for Disease Control and Prevention; $\mathrm{C}_{\mathrm{t}}$, cycle threshold; neg, negative; CV, coefficient of variation; $\mathrm{N}$, nucleocapsid protein gene; RP, ribonuclease $\mathrm{P}$ gene; rRT-PCR, real-time reverse

transcription PCR; SARS-CoV-2, severe acute respiratory coronavirus $2 ;$ TCID $_{50}, 50 \%$ tissue culture infectious dose.

$\dagger 50 \%$ tissue culture infectious dose $/ \mathrm{mL}$

\section{Discussion}

The COVID-19 pandemic has affected multiple countries, causing severe illness and death, with sustained and efficient person-to-person community transmission, and it continues to pose a serious public health threat. Rapid and reliable laboratory diagnosis of SARS-CoV-2 infection is a critical component of public health interventions to mitigate this threat.

Our assay design and validation strategy were guided by several principles. First, we based assay designs on previous diagnostic assays that had been developed for detection of MERS-CoV (12) and SARS-CoV (10) and targeted the N gene. Because of the relative abundance of $\mathrm{N}$ gene subgenomic mRNA produced during virus replication (13), rRT-PCR assays targeting the $\mathrm{N}$ gene of coronaviruses could theoretically achieve enhanced diagnostic sensitivity. One study also showed that the N gene-based rRTPCR assay was more sensitive than the open reading frame (ORF) 1 assay for detection of SARS-CoV-2 in clinical specimens (14). Second, we designed rRTPCR assays on the basis of limited genetic information available soon after the emergence of SARS-CoV-2, when it was announced that a novel coronavirus of zoonotic origin was described as being similar to
bat-SARS-like CoVs and only 1 SARS-CoV-2 sequence was publicly available. The N3 assay was intentionally designed to universally detect SARS-CoV-2 and other SARS-like sarbecoviruses to ensure detection of SARS-CoV-2 as this virus evolves over time and to improve early identification of future emerging novel coronaviruses from this high-risk subgenus. After completion of this study, the sequence of a new bat-SARS-like CoV, RaTG13 (EPI_SL_402131), was released on GISAID. Detected in 2013 from China, this virus appears to be the nearest bat precursor of SARS-CoV-2 (15), having 96\% genome and 97\% N gene sequence identity with SARS-CoV-2. All 3 assays are predicted to detect the RaTG13 strain. Third, we designed and used multiple assays for routine specimen screening to confirm virus detection when present at low concentrations and to reduce the possibility of false-negative results caused by polymorphisms within the binding sites of the target sequences, which might occur as the virus evolves. Fourth, we validated all assays by using multiple specimen types, including upper and lower respiratory specimens, serum, and stool samples, all of which have been shown to be diagnostically valuable for detection of SARS-CoV and MERS-CoV $(10,16)$.

Table 6. Nucleotide mismatches among 7,158 SARS-CoV-2 genome sequences found in the primer and probe regions included in the US CDC rRT-PCR panel for detection of SARS-CoV-2*

\begin{tabular}{|c|c|c|c|c|c|c|c|c|c|}
\hline Primer/probe & N1 probe & \multicolumn{2}{|c|}{ N1 reverse } & N2 forward & \multicolumn{2}{|c|}{ N3 forward } & \multicolumn{2}{|c|}{ N3 probe } & N3 reverse \\
\hline $\begin{array}{l}\text { Location, } 5^{\prime} \rightarrow 3^{\prime} \\
\end{array}$ & 3 & 15 & 21 & 4 & 8 & 10 & 5 & 17 & 14 \\
\hline Mismatch nucleotide & $C>T$ & $G>T$ & $\mathrm{~T}>\mathrm{C}$ & $C>T$ & $\mathrm{~T}>\mathrm{C}$ & $G>T$ & $\mathrm{C}>\mathrm{T}$ & $\mathrm{C}>\mathrm{T}$ & $C>A$ \\
\hline No. sequences & 39 & 22 & 33 & 7 & 111 & 7 & 7 & 9 & 22 \\
\hline Mismatch frequency, $\% \dagger$ & 0.54 & 0.31 & 0.46 & 0.10 & 1.55 & 0.10 & 0.10 & 0.13 & 0.31 \\
\hline
\end{tabular}


Table 7. Cross-reactivity of the US CDC rRT-PCR panel for detection of SARS-CoV-2 against other respiratory pathogens*

\begin{tabular}{|c|c|c|c|c|c|}
\hline \multirow[b]{2}{*}{ Pathogen (strain) } & \multirow[b]{2}{*}{ Source } & \multirow{2}{*}{$\begin{array}{c}\text { Other respiratory } \\
\text { pathogens, rRT-PCR }\left(\mathrm{C}_{\mathrm{t}}\right)\end{array}$} & \multicolumn{3}{|c|}{ SARS-CoV-2 rRT-PCR } \\
\hline & & & $\mathrm{N} 1$ & $\mathrm{~N} 2$ & N3 $\left(\mathrm{C}_{\mathrm{t}}\right)$ \\
\hline Adenovirus C1 (Ad.71) & Virus isolate & Pos (14.0) & Neg & Neg & $\mathrm{Neg}$ \\
\hline Bocavirus & Clinical specimen & Pos (14.9) & Neg & Neg & Neg \\
\hline Coronavirus 229E & Virus isolate & Pos (9.6) & Neg & Neg & Neg \\
\hline Coronavirus OC43 & Virus isolate & Pos (12.9) & Neg & Neg & Neg \\
\hline Coronavirus HKU1 & Clinical specimen & Pos (22.3) & Neg & Neg & Neg \\
\hline Coronavirus MERS & Virus isolate & Pos (14.3) & Neg & Neg & Neg \\
\hline Coronavirus NL63 & Clinical specimen & Pos (21.9) & Neg & Neg & Neg \\
\hline Coronavirus SARS (Urbani) & Virus isolate & Pos (27.3) & Neg & Neg & Pos (26.3)† \\
\hline Enterovirus D68 & Virus isolate & Pos (21.3) & Neg & Neg & Neg \\
\hline Human metapneumovirus (CAN 99-81) & Virus isolate & Pos (13.8) & Neg & Neg & Neg \\
\hline Influenza A H1N1 (A/India/2012) & Virus isolate & Pos (14.7) & Neg & Neg & Neg \\
\hline Influenza A H3N1 (A/Texas/2012) & Virus isolate & Pos (10.7) & Neg & Neg & Neg \\
\hline Influenza B (B/Massachusetts/1999) & Virus isolate & Pos (8.4) & Neg & Neg & Neg \\
\hline Parainfluenza 1 (C35) & Virus isolate & Pos (17.2) & Neg & Neg & Neg \\
\hline Parainfluenza 2 (Greer) & Virus isolate & Pos (17.1) & Neg & Neg & Neg \\
\hline Parainfluenza 3 (C-43) & Virus isolate & Pos (20.4) & Neg & Neg & Neg \\
\hline Parainfluenza 4a (M-25) & Virus isolate & Pos (16.7) & Neg & Neg & Neg \\
\hline Parainfluenza 4b (CH 19503) & Virus isolate & Pos (18.2) & Neg & Neg & Neg \\
\hline Respiratory syncytial virus (Long) & Virus isolate & Pos (15.1) & Neg & Neg & Neg \\
\hline Rhinovirus $1 \mathrm{~A}$ & Virus isolate & Pos (15.9) & Neg & Neg & Neg \\
\hline Mycoplasma pneumoniae & Cultured bacteria & Pos (20.7) & Neg & Neg & Neg \\
\hline Streptococcus pneumoniae & Cultured bacteria & Pos (21.1) & Neg & Neg & Neg \\
\hline $\begin{array}{l}{ }^{*} \mathrm{CDC} \text {, Centers for Disease Control and Pre } \\
\text { nucleocapsid protein gene; rRT-PCR, real-ti } \\
\text { †N3 assay designed for universal detection } \\
\text { SARS-like coronaviruses. }\end{array}$ & $\begin{array}{l}\text { cycle threshold; neg, } \\
\text { transcription PCR; SA } \\
\text { nd } 3 \text { within Sarbecovi }\end{array}$ & $\begin{array}{l}\text { ositive; MERS, } \\
\text { vere acute resp }\end{array}$ & & & $\begin{array}{l}\text { e; } N \\
\text { d civet- }\end{array}$ \\
\hline
\end{tabular}

A study of SARS-CoV-2 viral load in upper respiratory tract specimens of infected patients showed that viral loads were higher in the nasopharynx than in the throat (17). Our study also showed a higher detection rate for nasopharyngeal swab samples than for oropharyngeal swab samples, although in some cases, viral load was higher in oropharyngeal than in nasopharyngeal swab samples. Our limited sputum data showed that SARS-CoV-2 seems to be more often detected and with higher viral loads in lower respiratory tract specimens than in upper respiratory tract specimens, especially later in the course of infection $(72.22 \%$ positivity rate for sputum compared with $46.51 \%$ for nasopharyngeal and $30.00 \%$ for oropharyngeal samples in serial follow-up specimens). This phenomenon could be explained by the active replication of SARS-CoV-2 in the lungs,

\begin{tabular}{|c|c|c|c|c|c|c|c|c|}
\hline \multirow[b]{2}{*}{ Specimens } & \multicolumn{4}{|c|}{ Specimens for initial laboratory diagnosis, no. (\%) } & \multicolumn{4}{|c|}{$\begin{array}{l}\text { Serial follow-up specimens from laboratory- } \\
\text { confirmed positive cases, no. }(\%)\end{array}$} \\
\hline & Positive & Negative & Inconclusive & Total & Positive & Negative & Inconclusive & Total \\
\hline \multicolumn{9}{|c|}{ Upper respiratory tract } \\
\hline NP swab & $42(3.85)$ & $1,048(96.06)$ & $1(0.09)$ & $1,091(100)$ & $60(46.51)$ & $50(38.76)$ & $19(14.73)$ & $129(100)$ \\
\hline OP swab & 33 (3.09) & $1,035(96.91)$ & 0 & $1,068(100)$ & $42(30.00)$ & $86(61.43)$ & $12(8.57)$ & $140(100)$ \\
\hline $\begin{array}{l}\text { Nasal } \\
\text { swab/wash }\end{array}$ & 0 & $7(100)$ & 0 & $7(100)$ & 0 & 0 & 0 & 0 \\
\hline \multicolumn{9}{|c|}{ Lower respiratory tract } \\
\hline Sputum & $5(2.79)$ & $174(97.21)$ & 0 & $179(100)$ & $13(72.22)$ & $3(16.67)$ & $2(11.11)$ & $18(100)$ \\
\hline BAL & $1(50)$ & $1(50)$ & 0 & $2(100)$ & 0 & 0 & 0 & 0 \\
\hline Bronchial wash & 0 & $1(100)$ & 0 & $1(100)$ & 0 & 0 & 0 & 0 \\
\hline Tissue, lung & 0 & $2(100)$ & 0 & $2(100)$ & 0 & 0 & 0 & 0 \\
\hline $\begin{array}{l}\text { Tracheal } \\
\text { aspirate }\end{array}$ & 0 & 0 & 0 & 0 & $1(100)$ & 0 & 0 & $1(100)$ \\
\hline \multicolumn{9}{|l|}{ Other } \\
\hline Serum & 0 & $74(100)$ & 0 & $74(100)$ & $4(4.88)$ & $76(92.68)$ & $2(2.44)$ & $82(100)$ \\
\hline Stool & 0 & 0 & 0 & 0 & $22(40.74)$ & $28(51.85)$ & $4(7.41)$ & $54(100)$ \\
\hline Urine & 0 & $10(100)$ & 0 & $10(100)$ & 0 & $62(100)$ & 0 & $62(100)$ \\
\hline Pleural fluid & 0 & $1(100)$ & 0 & $1(100)$ & 0 & 0 & 0 & 0 \\
\hline CSF & 0 & $2(100)$ & 0 & $2(100)$ & 0 & 0 & 0 & 0 \\
\hline Total & 81 (3.32) & $2,355(96.64)$ & $1(0.04)$ & $2,437(100)$ & $142(29.22)$ & $305(62.76)$ & 39 (8.02) & $486(100)$ \\
\hline
\end{tabular}


where the SARS-CoV-2 angiotensin-converting enzyme 2 receptor predominates (18). Similar to findings for SARS-CoV (19), our results showed that the SARS-CoV-2 RNA detection rate was high in the serial follow-up stool specimens collected from casepatients with laboratory-confirmed COVID-19. In contrast, SARS-CoV and MERS-CoV could be detected in serum/blood during the early prodromal phase of infection $(12,20)$, whereas SARSCoV-2 RNA was not detected in any of the serum
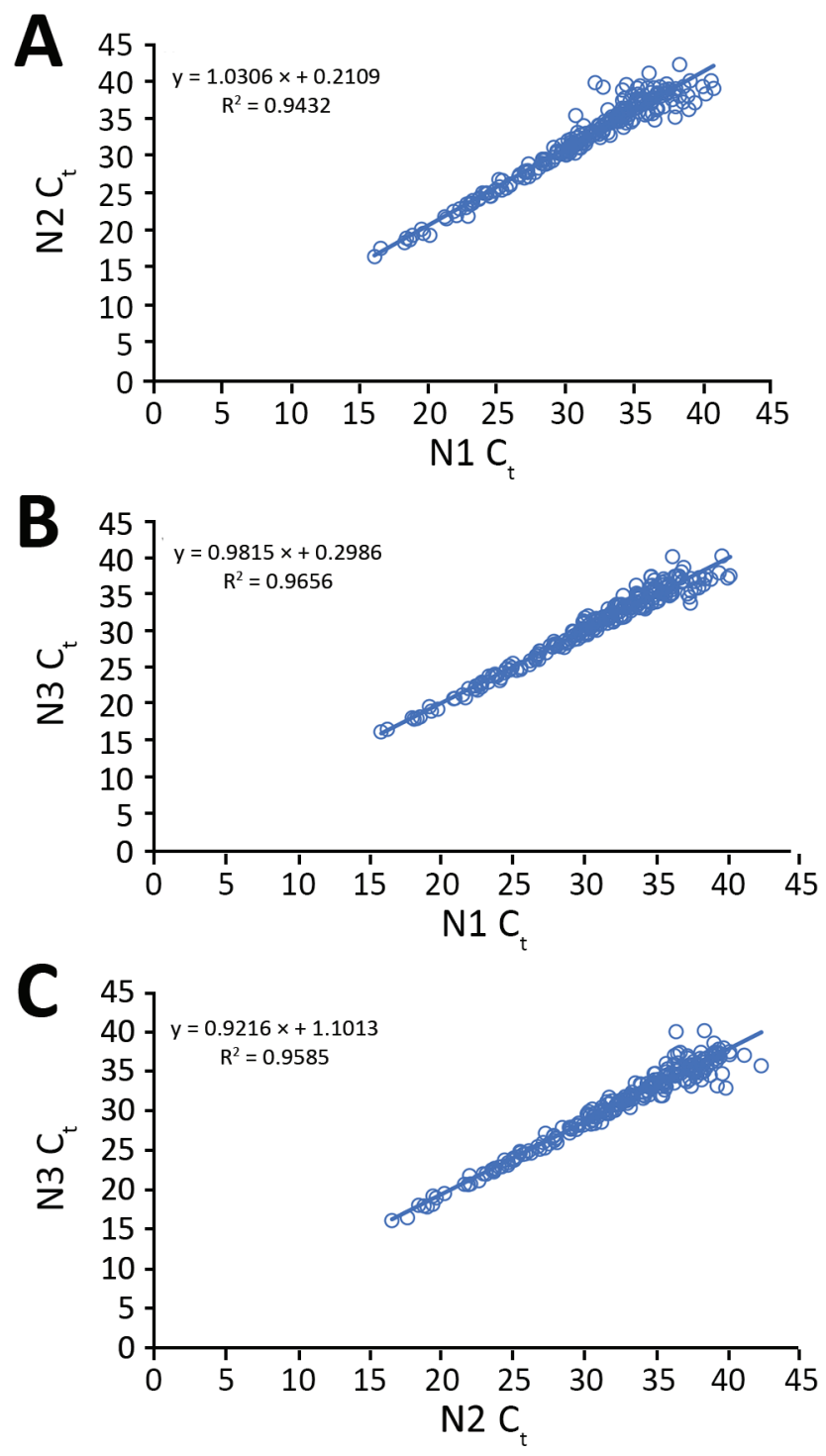

Figure 2. Comparison of the N1, N2, and N3 assays in the US Centers for Disease Control and Prevention real-time reverse transcription PCR panel for detection of SARS-CoV-2 with 223 SARS-CoV-2-positive clinical specimens. Linear regression lines were fitted to $C_{t}$ values, with regression equations and coefficients of determination $\left(R^{2}\right)$. A) N1 vs. N2; B) N1 vs. N3; C) N2 vs. N3. $C_{t}$, cycle threshold; SARS-CoV-2, severe acute respiratory syndrome coronavirus 2 . specimens during the initial testing, although it was detected in serum collected from 2 (13.3\%) case-patients $\geq 9$ days after symptom onset. Similarly, whereas SARS-CoV and MERS-CoV RNA have been detected in urine $(16,19)$, SARS-CoV-2 RNA was not detected in urine in our study nor has detection been reported (21).

All specimens with inconclusive results in our study had $C_{t}$ values $>35$, with reactivity not attributable to 1 individual assay, indicating that the viral RNA levels in the specimens were at the LoD of the assay. All specimens with inconclusive results were collected either $\geq 7$ days after symptom onset or from repatriates who had been quarantined on the Diamond Princess cruise ship for $\approx 2$ weeks before specimen collection. Inconclusive results most likely resulted from low viral loads, especially in upper respiratory tract specimens collected later in the course of infection. This observation is supported by another study, which showed that SARS-CoV-2 actively replicated in the oropharynx during the first 5 days after symptoms onset only (21). If inconclusive results are obtained, collection of additional specimens and specimen types may be warranted for accurate diagnosis.

All 3 SARS-CoV-2 rRT-PCR assays proved to be both sensitive and specific with high reproducibility. The earliest specimens from US COVID-19 case-patients were confirmed by virus isolation, whole-genome or partial gene sequencing, or both (22) (GenBank accession nos. MN985325, MN988713, MN994467-8, MN997409, MT027062-4, MT039887-8, MT044257-8, MT106052-4, MT118835, MT159705-22, and MT184907-13), although not all positive followup specimens detected by rRT-PCR assays were confirmed by independent assays. An independent comparison study showed that the CDC N2 and N3 assays performed well among 7 assays targeting the $\mathrm{N}$ gene that were evaluated and posted by the World Health Organization (Y. Jung, unpub. data, https://www. biorxiv.org/content/10.1101/2020.02.25.964775v1). In another study that compared 7 assays, the N2 assay was shown to be among the most sensitive (23). However, both studies used enzyme chemistries not optimized by CDC for testing, and we did not observe difference in sensitivity among the 3 assays in our study.

To expedite reagent kit manufacturing by removal of the N3 assay from the panel, we analyzed results of 2,437 specimens for initial COVID-19 testing when only N1 and N2 assay results were used for interpretation. Positive and negative test results showed 100\% agreement to interpretation with all 3 assays. Only 1 $(0.04 \%)$ specimen with an inconclusive result, which was positive for $\mathrm{N} 2$ at initial testing and positive for 
$\mathrm{N} 3$ at retesting, would be reported as negative if the N3 assay was excluded from result interpretation of the CDC panel. This analysis demonstrates that interpretation of only N1 and N2 assay results agreed totally $(99.96 \%)$ with the original results, and removal of the N3 assay from the panel would have a negligible effect on the ability of the test to detect positive specimens. The analytical LoD of the panel remained the same for detection of SARS-CoV-2 with or without the N3 assay included, and sensitivity of the panel was not affected. The benefits of testing with only N1 and $\mathrm{N} 2$ assays include simplified diagnosis of COVID-19 with fewer reactions for each patient specimen as well as increased testing throughput and reduced reagent cost, although removal of the N3 assay from the panel limits the ability to detect other SARS-like coronaviruses. Accordingly, the N3 assay has been removed from CDC testing interpretation, and current recommendations are to test with the N1 and N2 assays only (11). Because SARS-CoV-2 is an RNA virus with an estimated evolutionary rate of $\approx 1.8 \times 10^{-3}$ substitutions/site/year (24), performance of the assays included in the CDC panel will be monitored as SARS-CoV-2 continues to circulate and evolve over time. Therefore, assay designs included in the CDC panel are subject to change to account for future genetic mutations in the SARS-CoV-2 genome that may affect test sensitivity.

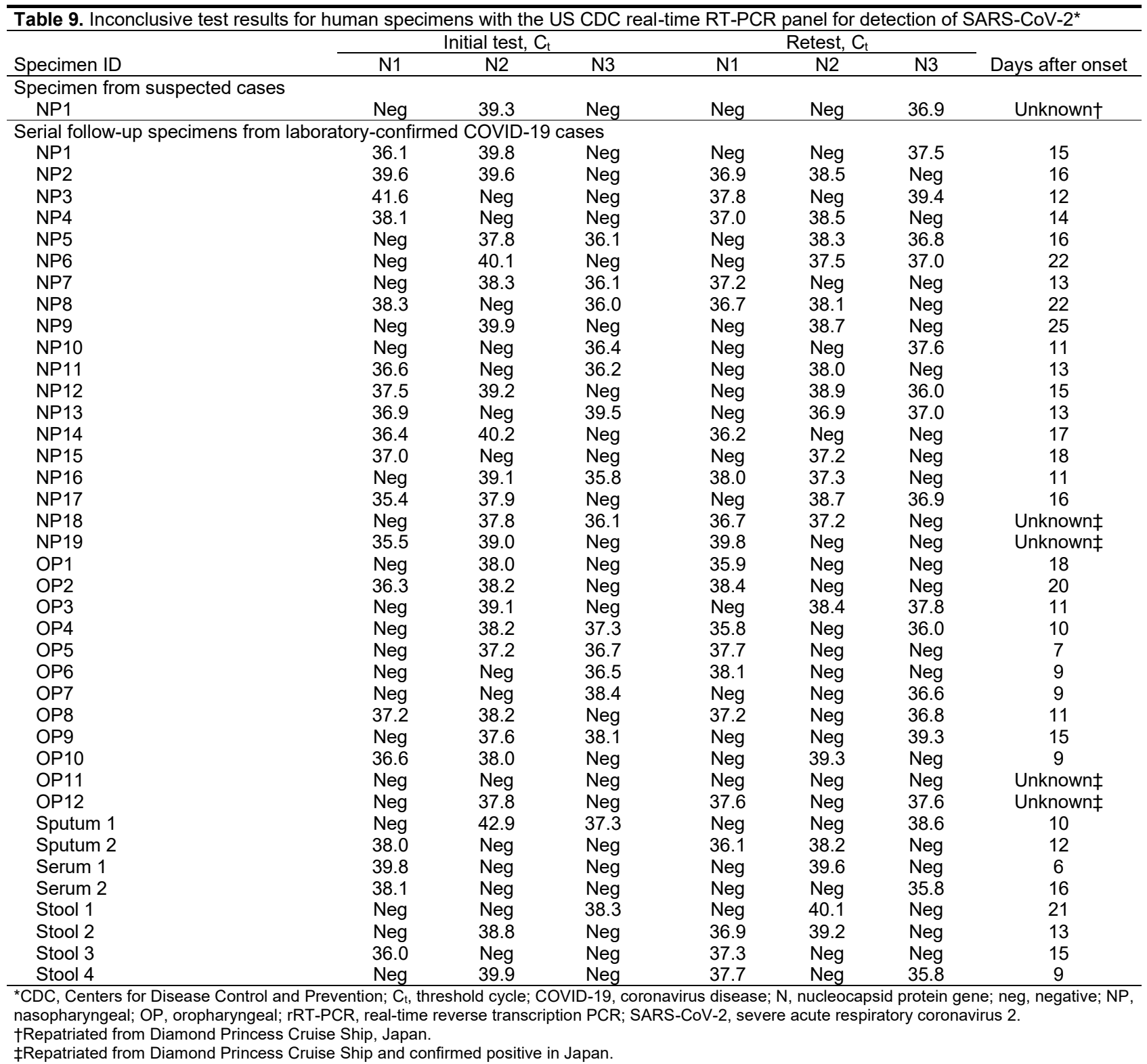


In conclusion, the CDC rRT-PCR panel for detection of SARS-CoV-2 demonstrated high sensitivity and specificity for detecting 5 RNA copies/reaction with no observed false-positive reactivity, and it facilitated rapid detection of SARS-CoV-2 infections in humans. These assays have proven to be valuable for rapid laboratory diagnosis and support, clinical management, and infection prevention and control of COVID-19.

\section{Acknowledgments}

We thank those who contributed substantially to this effort, including Nicky Sulaiman, Mathew Esona, Sung-Sil Moon, Yange Zhang, Jennifer Thomas, Laurel Jenkins, Mila Cohen, Hsin Chien, How-Yi Chang, Shannon York, and Nazia Kamal. We also thank all authors who have kindly shared genome data on GISAID.

Names of specific vendors, manufacturers, or products are included for public health and informational purposes; inclusion does not imply CDC endorsement of the vendors, manufacturers, or products. X.L. and S.L. have submitted the technology to the CDC Technology Transfer Office to ensure public health access to the technology and to facilitate its access to commercial developers.

\section{About the Author}

Ms. Lu is a research microbiologist with the National Center for Immunization and Respiratory Diseases, CDC, in Atlanta, Georgia. Her research interests include development and application of novel technologies to study the molecular epidemiology of human respiratory viruses, including adenoviruses, rhinoviruses, and emerging coronaviruses.

\section{References}

1. World Health Organization. Pneumonia of unknown causeChina [cited 2020 Mar 1]. https:/ / www.who.int/csr/don/ 05-january-2020-pneumonia-of-unkown-cause-china

2. Zhu N, Zhang D, Wang W, Li X, Yang B, Song J, et al.; China Novel Coronavirus Investigating and Research Team. A novel coronavirus from patients with pneumonia in China, 2019. N Engl J Med. 2020;382:727-33. https:/ / doi.org/ 10.1056/NEJMoa2001017

3. Zhang Y-Z. Novel 2019 coronavirus genome. Virological. 2020 Jan 10 [cited 2020 Mar 1]. http:/ / virological.org/t/ novel-2019-coronavirus-genome/319

4. Lu R, Zhao X, Li J, Niu P, Yang B, Wu H, et al. Genomic characterisation and epidemiology of 2019 novel coronavirus: implications for virus origins and receptor binding. Lancet. 2020;395:565-74. https:/ / doi.org/10.1016/ S0140-6736(20)30251-8

5. Chan JF, Kok KH, Zhu Z, Chu H, To KK, Yuan S, et al. Genomic characterization of the 2019 novel humanpathogenic coronavirus isolated from a patient with atypical pneumonia after visiting Wuhan. Emerg Microbes Infect. 2020;9:221-36. https://doi.org/10.1080/22221751.2020.1719902
6. Holshue ML, DeBolt C, Lindquist S, Lofy KH, Wiesman J, Bruce H, et al.; Washington State 2019-nCoV Case Investigation Team. First case of 2019 novel coronavirus in the United States. N Engl J Med. 2020;382:929-36. https:// doi.org/10.1056/NEJMoa2001191

7. World Health Organization. Coronavirus disease 2019 (COVID-19) situation report-93 [cited 2020 Apr 22]. https://www.who.int/docs/default-source/coronaviruse/situation-reports/20200422-sitrep-93-covid-19. pdf?sfvrsn=35cf80d7_4

8. Harcourt J, Tamin A, Lu X, Kamili S, Sakthivel SK, Murray J, et al. Severe acute respiratory syndrome coronavirus 2 from patient with 2019 novel coronavirus disease, United States. Emerg Infect Dis. 2020 Mar 11 [Epub ahead of print]. https://doi.org/10.3201/eid2606.200516

9. Centers for Disease Control and Prevention. Health Alert Network: update and interim guidance on outbreak of 2019 novel coronavirus (2019-nCoV) in Wuhan, China [cited 2020 Apr 16]. https://emergency.cdc.gov/han/han00426.asp

10. Emery SL, Erdman DD, Bowen MD, Newton BR, Winchell JM, Meyer RF, et al. Real-time reverse transcription-polymerase chain reaction assay for SARSassociated coronavirus. Emerg Infect Dis. 2004;10:311-6. https://doi.org/10.3201/eid1002.030759

11. Centers for Disease Control and Prevention. CDC 2019novel coronavirus (2019-nCoV) real-time RT-PCR diagnostic panel [cited 2020 Mar 1]. https:/ / www.fda.gov/ media/134922/download

12. Lu X, Whitaker B, Sakthivel SK, Kamili S, Rose LE, Lowe L, et al. Real-time reverse transcription-PCR assay panel for Middle East respiratory syndrome coronavirus. J Clin Microbiol. 2014;52:67-75. https://doi.org/10.1128/ JCM.02533-13

13. Moreno JL, Zúñiga S, Enjuanes L, Sola I. Identification of a coronavirus transcription enhancer. J Virol. 2008;82:3882-93. https:// doi.org/10.1128/JVI.02622-07

14. Chu DKW, Pan Y, Cheng SMS, Hui KPY, Krishnan P, Liu Y, et al. Molecular diagnosis of a novel coronavirus (2019-nCoV) causing an outbreak of pneumonia. Clin Chem. 2020;66:549-55. https://doi.org/10.1093/clinchem/hvaa029

15. Zhou P, Yang XL, Wang XG, Hu B, Zhang L, Zhang W, et al. A pneumonia outbreak associated with a new coronavirus of probable bat origin. Nature. 2020;579:270-3. https:/ / doi.org/10.1038/s41586-020-2012-7

16. Al-Abdely HM, Midgley CM, Alkhamis AM, Abedi GR, Lu X, Binder AM, et al. Middle East respiratory syndrome coronavirus infection dynamics and antibody responses among clinically diverse patients, Saudi Arabia. Emerg Infect Dis. 2019;25:753-66. https:// doi.org/10.3201/eid2504.181595

17. Zou L, Ruan F, Huang M, Liang L, Huang H, Hong Z, et al. SARS-CoV-2 viral load in upper respiratory specimens of infected patients. N Engl J Med. 2020;382:1177-9. https://doi.org/10.1056/NEJMc2001737

18. Hamming I, Timens W, Bulthuis ML, Lely AT, Navis G, van Goor H. Tissue distribution of ACE2 protein, the functional receptor for SARS coronavirus. A first step in understanding SARS pathogenesis. J Pathol. 2004;203:631-7. https:/ / doi.org/10.1002/path.1570

19. Chan KH, Poon LL, Cheng VC, Guan Y, Hung IF, Kong J, et al. Detection of SARS coronavirus in patients with suspected SARS. Emerg Infect Dis. 2004;10:294-9. https:// doi.org/10.3201/eid1002.030610

20. Grant PR, Garson JA, Tedder RS, Chan PK, Tam JS, Sung JJ. Detection of SARS coronavirus in plasma by real-time RT-PCR. N Engl J Med. 2003;349:2468-9. https:/ / doi.org/10.1056/NEJM200312183492522 
21. Wölfel R, Corman VM, Guggemos W, Seilmaier M, Zange S, Müller MA, et al. Virological assessment of hospitalized cases of coronavirus disease 2019. Nature. 2020 Apr 1 [Epub ahead of print].

22. Kujawski SA, Wong KK, Collins, JP. Clinical and virologic characteristics of the first 12 patients with coronavirus disease 2019 (COVID-19) in the United States. Nat Med. 2020 Apr 23 [Epub ahead of print]. https:/ / doi.org/10.1038/ s41591-020-0877-5

23. Nalla AK, Casto AM, Huang MW, Perchetti GA, Sampoleo R, Shrestha L, et al. Comparative performance of SARS-CoV-2 detection assays using seven different primer/probe sets and one assay kit. J Clin Microbiol. 2020 Apr 8 [Epub ahead of print].

24. Li X, Wang W, Zhao X, Zai J, Zhao Q, Li Y, et al. Transmission dynamics and evolutionary history of 2019-nCoV. J Med Virol. 2020;92:501-11. https:// doi.org/10.1002/jmv.25701

Address for correspondence: Stephen Lindstrom, Centers for Disease Control and Prevention, 1600 Clifton Rd NE, Mailstop G04, Atlanta, GA 30329-4027, USA; email: sq15@cdc.gov

\section{EID Podcast How and Why Social Distancing Works}

In the wake of the COVID-19 pandemic, it can be difficult to discern the science underlying the news reports. Yet it is crucial that people understand concepts like social distancing and flattening the curve-and lives depend on it.

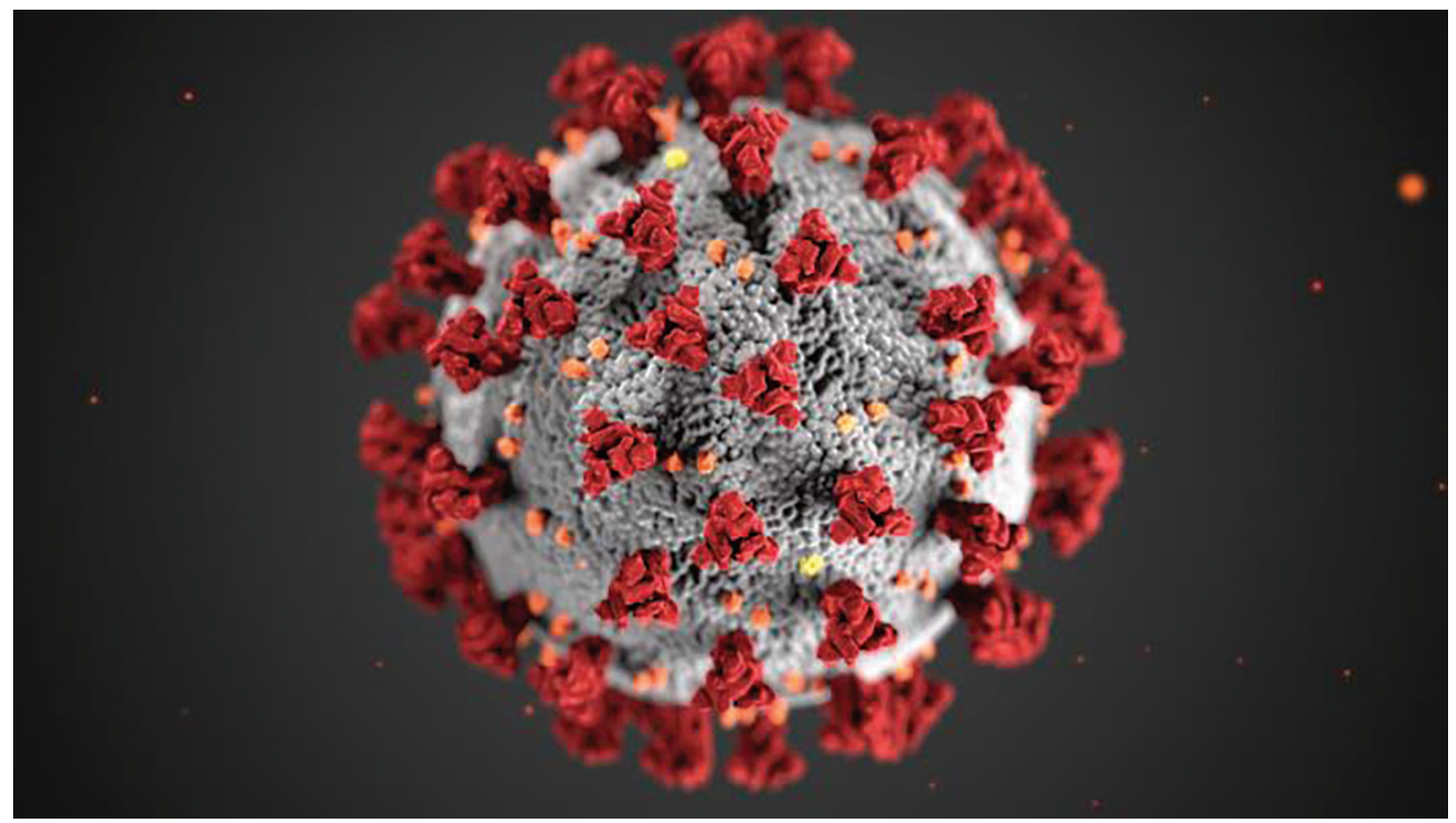

In this EID podcast, Dr. Laura Matrajt, a research associate at the Fred Hutchinson Cancer Research Center, explains the science behind social distancing.

\section{Visit our website to listen: EMERCING https://go.usa.gov/xw9He INFECTIOUS DISEASES}

